\title{
Immunopathogenesis, Immunomodulation and Management of Immune Thrombocytopenic Purpura in Children
}

\author{
a report by
}

Paul A Imbach

University Children's Hospital Basel

The bleeding disorder immune thrombocytopenic purpura (ITP) is a model for immunological research and new biological treatment modalities of chronic inflammatory and autoimmune disorders. In ITP, immunologically susceptible subjects are recognisable by disturbances of the immune response on various levels. Children have mostly a transient or persistent form (below 12 months' duration) and rarely have a chronic form of ITP. Children without bleedings may be observed without treatment or may need treatment according to a staging and management schedule (see Table 1).

Therapeutically, the immune cascade can be modulated on various levels by human immunoglobulins (Igs), anti-D Igs, corticosteroids, Tcell suppression, monoclonal anti-CD 20 or 52 antibodies or others. Agonists stimulating growth of thrombopoietin-dependent cell lines that increase platelet counts might soon be available, mainly for patients with severe persistent, refractory or chronic ITP. This article highlights and updates immunopathological findings and proposes a management procedure for children with short-term or refractory ITP.

\section{Definition and Incidence}

ITP is a bleeding disorder characterised by platelet destruction due to (auto-)antibody binding resulting in early platelet phagocytosis. ITP occurs in primary and secondary forms. The primary form is an isolated thrombocytopenia in an otherwise healthy individual. The secondary form includes all other ITP (e.g. lupus-, HIV- and drug-related ITP).

The severity of ITP depends on bleeding symptoms. In children, ITP is mostly a para- or a post-infectious transient event. A minority of children have a persistent or chronic form of ITP similar to the majority of adolescents and adults. An international expert group conducted by Francesco Rodeghiero and with the backing of the European Hematology Association (EHA) if working an recommendations and terminology.

The incidence in children with newly diagnosed ITP is estimated to be 5.3-5.7 patients per 100,000 children per year. ${ }^{1,2}$ At diagnosis, $55 \%$ of boys and $45 \%$ of girls were registered prospectively; in infancy the number of boys was dramatically higher. ${ }^{3}$ Incidence, duration and severity vary from continent to continent. A comparison between Vietnamese and European children with chronic ITP showed marked differences. ${ }^{4}$

\section{Pathophysiology of Immune Thrombocytopenic Purpura}

In patients with ITP the maintenance of self-tolerance and the effective immune response seems to be altered in the presence of an inflammatory or autoimmune process. In ITP, circulating antibodies and/or immuncomplexes adsorb to the platelet specifically via the fragment antigen binding ( $\mathrm{Fab}$ ) region of the antibody to glycoprotein-epitopes on platelets or unspecifically via the Fc part of the IgG molecules, resulting in early opsonophagocytosis and destruction by macrophages. ${ }^{5}$ The quantity of early platelet destruction and platelet production correlate with the degree of thrombocytopenia and bleeding.

In ITP and many other inflammatory and autoimmune disorders, multiple possibilities of disturbances on the different levels of the immune cascade are documented, especially in connection with intravenous lg (IVIg) treatment: $6,7,8,9$ on the level of antigen presentation, T-cell activation and signalling, B-cell regulation and antibodies/idiotypic antibodies production, activation/suppression of complement, opsonophagocytosis and apoptosis (see Table 2). These recognised alterations were used to develop new treatment modalities for many autoimmune disorders. A recent observation of ITP triggered by Helicobacter pylori illustrates the complexity of the immune response in susceptible patients, the host response and the country differences..$^{10,11}$ The aetiology of ITP is still unknown, and why some children are susceptible and others not may be a question of moleculargenetic alterations. First analyses support moleculargenetic abnormalities of the immune response in ITP. ${ }^{12-14}$

\section{Significance of Immunological Aspects and of Growth Factors in Immune Thrombocytopenic Purpura}

Three main developments made ITP a model of pathophysiology and treatment in inflammatory and autoimmune disorders within the last 60 years. In 1950, the causative platelet destructive factor was found by transfusion of blood/plasma from patients with chronic ITP to volunteers with normal platelet counts. The recipients developed transient thrombocytopenia. ${ }^{15,16}$ Later on, the causative factor was characterised as antibodies against epitopes, often against antigenic platelet glycoproteins. In 1980, a boy with long-term, severe ITP bleeding and secondary, iatrogenic hypogammaglobulinaemia due to immunosuppressive treatment showed a dramatic platelet increase after the substitution of antibody concentrate from healthy blood donors, the new IVIG. This was also the case in 12 consecutively IVIG treated normogammaglobulinaemic children with ITP. ${ }^{17}$ This observation was confirmed by a controlled multicentre study. ${ }^{18}$ This

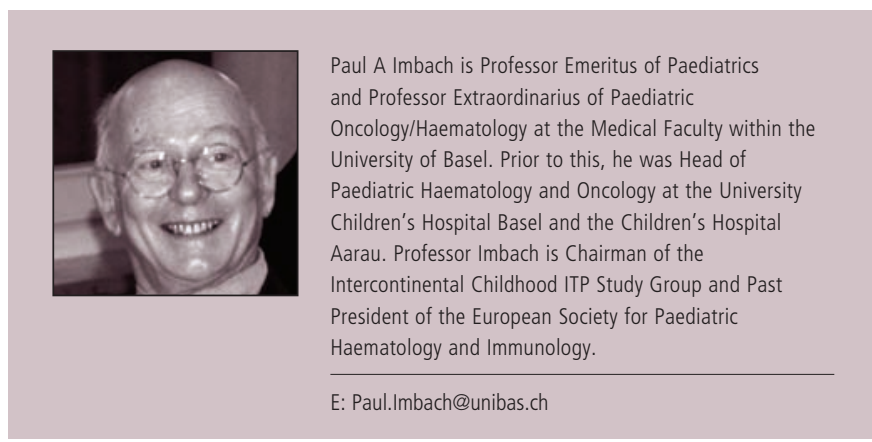


Table 1: Staging and Management of Patients with Immune Thrombocytopenic Purpura

\begin{tabular}{llr}
\hline Stages/Bleeding & Platelet $\left(\times 10^{9} /\right)$ & Management \\
\hline $\begin{array}{l}\text { 1. Minor/mild bleeding, } \\
\text { normal lifestyle }\end{array}$ & $>10-20$ & Consent for observation \\
\hline $\begin{array}{l}\text { 2. Moderate bleeding, } \\
\text { troublesome lifestyle }\end{array}$ & $<10-20$ & Punctual intervention \\
$\begin{array}{l}\text { 3. Severe, life-threatening } \\
\text { bleeding }\end{array}$ & Mostly $<10$ & Intervention \\
\hline
\end{tabular}

Figure 1: ICIS Registry 1 - Follow-up of 308/2,031 Children with Ongoing Immune Thrombocytopenic Purpura Six to 12 Months After Diagnosis - Platelet Count (x109/I)

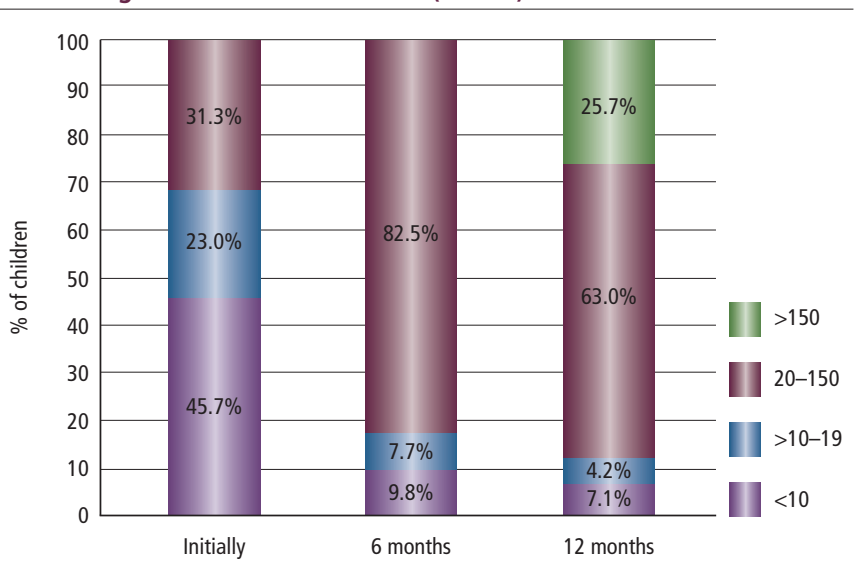

Source: Pediatr Blood Cancer, 2006:46:351

was the first targeted immunomodulation, which today is used in a broad field of chronic inflammatory and autoimmune diseases. ${ }^{6-9}$ In 1980, 300kg of IVIG was produced worldwide, which increased to over 60 tons until 2007 (personal communication by CSL Behring).

In 1994, thrombopoietic growth factor has been developed and its administration increased platelet counts in volunteers. ${ }^{19}$ This first generation of thrombopoietic growth factor as recombinant human thrombopoietin (rhTPO) and as pegylated human recombinant megakaryocyte growth and development factor PEG rHu MGDF had to be stopped in clinical trials when autoantibodies against the administered factor (PEG rHu MGDF) were detected in healthy human subjects. A second generation of thrombopoietin-receptor agonists (AMG 531 for subcutaneous use, eltrombopag and AKR 501 for oral use and others) stimulate growth of thrombopoietin-dependent cell lines and increase platelet counts. Within the last five years these second-generation thrombopoietic factors have demonstrated safety, tolerability and efficacy in patients with ITP. ${ }^{19}$ Further studies (long-term application, activation of platelet function etc.) have to be concluded before approval for clinical use of these agent will be released.

Although the serum level of thrombopoietin of patients with ITP is normal or slightly increased, recent in vitro studies showed reduced megakaryocyte production and impaired maturation in the presence of ITP plasma-containing autoantibodies against platelets ${ }^{20}$ - apparently a reason for efficacy in patients with ITP.

\section{Clinical Manifestation of Immune} Thrombocytopenic Purpura

The clinical manifestation, severity of bleeding and platelet count and the natural history of ITP are heterogenous. Child patients and their parents are
Table 2: Summary of Immunomodulation

\begin{tabular}{|c|c|c|}
\hline Immunomodulation & Examples & References \\
\hline Antigen suppression Fcr on & Antibiotics, virostatics, IVIG & $11,56,57,58$, \\
\hline dentritic cells activation & & $59,60,61,62$ \\
\hline \multicolumn{3}{|l|}{ Toll like receptor } \\
\hline Inhibition of T cells & Cyclosporin A, & $63,64,65,66$, \\
\hline and signalling & tacrolimus, IVIG & 67,68 \\
\hline Regulation of autoreacitve B cells & Anti-CD20/-CD52 & $42,44,45,69$, \\
\hline and anti-idiotype network & Antiidiotypic antibodies, IVIG & $70,71,72,73$ \\
\hline Modulation of: & Anti-D IgG, IVIG & $9,34,74,75$, \\
\hline - phagocytosis & & $76,77,78$ \\
\hline \multicolumn{3}{|l|}{ - complement } \\
\hline - apoptosis & & \\
\hline
\end{tabular}

Figure 2: Cascade of Immune Response

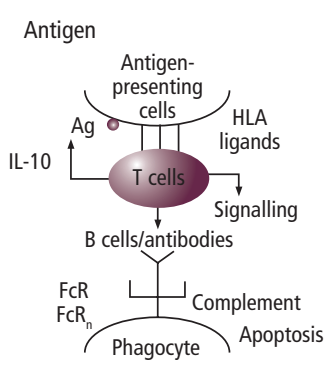

Table 3: Routine Testing in Addition to Initial Laboratory Analysis in Children with Persistent Immune Thrombocytopenic Purpura of Three to Six Months' Duration

Bone marrow analysis, endocrine function, urine analysis, abdominal ultrasound Antinuclear antibody, direct antiglobin, lupus anticoagulant, platelet antigen-specific antibodies, serum immunoglobulins with lgG subclasses, platelet function test, coagulation studies Viral serology (HIV, CMV, EBV, VZV, rubeola, parvovirus B19 and others)

fearful of bleeding and tyrannised by low platelet counts. The outcome of the individual patient cannot be predicted, although most children and some adults show spontaneous resolvement or improvement of ITP.

In two prospective Intercontintental Childhood ITP (ICIS) registries with newly diagnosed children ( $n=2,031$ and 1,015, respectively) two-thirds of patients initially had platelet counts below 20x109/.2 In Registry II 20 of 629 patients (3.2\%) had severe bleeding, 150 (23.6\%) showed moderate bleeding and 459 (73\%) showed mild or no bleeding initially. ${ }^{21}$ This is in accordance with the British assessment ${ }^{22}$ and a single-centre analysis in the US. ${ }^{23}$ Intracranial bleeding occurs in about 1:500-700 children, and is fatal in one-third. ${ }^{24}$ The initial management (mean platelet counts) in ICIS registry I was as follows: about one-third of children received IVIG $(8.1 \times 109 / 1)$ and one-third corticosteroids $(13.3 \times 109 /)$, and the remaining one-third were observed $\left(28.6 \times 10^{9} / I\right) .^{2}$ In children with persistent ITP of three to six months in duration, additional laboratory tests are recommended (see Table 1).

Unlike ITP in adults, persistent thrombocytopenia is observed in 20-30\% of children and the rate of severe ITP is decreasing with duration of ITP (see Figure 1). In the above-mentioned registry I, follow-up data 12 months after diagnosis was evaluable for 308 children with persistent ITP at six months. ${ }^{25}$ Between six and 12 months from diagnosis, 79 of the 308 children (25.6\%)

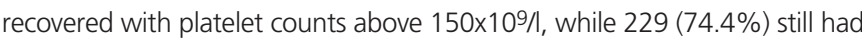
persistent ITP. The distribution of platelet counts at diagnosis at six and 12 months showed that the number of children with platelet counts below 10 and $20 \times 109 / /$ markedly decreased within the first 12 months of diagnosis. 
Thus, a reduction of severity of ITP over time was observed. In retrospective analyses, even after one year children recovered from their ITP. ${ }^{26-29}$ These observations raise the question whether the term 'chronic' ITP - now defined as persisting for six months after diagnosis - should be postponed to 12 months or longer. On the other hand, at 12 months after diagnosis in registry I, $11.3 \%$ of children still had platelet counts below $20 \times 109 /$ despite treatment. These children have refractory ITP.

\section{Management}

Since 1980, the therapeutic intervention of ITP has been challenged by the rapid effect of IVIG administration (see above). Today therapeutic approaches are targeted to the disturbed immune response (see Table 1): antigens are eliminated by antibiotics or antiviral drugs; lymphocyte functions are downmodulated by cyclosporine A or tacrolimus; B cells and antibody generation are modified by monoclonal antibodies (e.g. anti-CD-20, anti-CD 52); phagocytosis is competitively decreased by anti-D Igs; and IVIG alters the immune response on various levels (see Table 2 and Figure 2).

While the infusion of IVIG or anti-D have rapid immunomodulatory effects (platelet increase within one to three days), the platelet stimulatory effect occurs five to 14 days after starting thrombopoietin agonist. In the near future, the stimulation of thrombopoiesis will eventually be an additional approach. For practical patient care a simple categorisation of the clinical severity of ITP is necessary and should be validated. A proposal is 'staging and management' based on bleedings ${ }^{22}$ and quality of life ${ }^{30}$ rather than on platelet counts (see Table 1). In stages 2 and 3, consensus between the individual patients and physicians should be reached. For interventional management the following procedures may be used. ${ }^{31}$ Standard treatment includes: ${ }^{32}$

- IVIG 0.4-0.8g/kg bodyweight (bw) once;

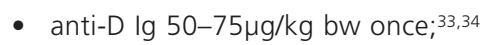

- corticosteroids $4 \mathrm{mg} / \mathrm{kg}$ bw daily for two to four days, then tapering for three days; and

- (thrombopoietin-receptor agonist):35-40 available in the US.

Where emergency treatment is needed in cases of severe lifethreatening bleeding, treatment should:

- begin with corticosteroids $30 \mathrm{mg} / \mathrm{kg}$ bw or dexamethason $1-2 \mathrm{mg} / \mathrm{kg} \mathrm{bw} ;{ }^{41}$

- progress to IVIG 0.8-1.0g/kg bw per dose; and ${ }^{41}$

- include a platelet transfusion after the above measures.
In cases of refractory ITP, treatment should include:

- (thrombopoietin agonist): ${ }^{35-40}$ available in the US;

- anti-CD 20-, anti-CD 52-monoclonal antibody for the suppression of B-cells; $42-45$

- cyclosporine A $2-5 \mathrm{mg} / \mathrm{kg}$ bw per day tacrolimus for the suppression of T-cells;

- vincristin IV $1.5 \mathrm{mg}$ (2mg maximum)/ $/ \mathrm{m}^{2}$ four to six times weekly plus $2 \mathrm{mg}$ corticosteroid/kg/bw/day three times per week;

- interferon, mycophenolate mofetil, ${ }^{46}$ high-dose corticosteroids or dexamethasone should also be considered; 47

- splenectomy; and ${ }^{48}$

- classic options (individual indications) such as azathioprime and cyclophosphamide.

\section{Clinical Research}

There is a considerable amount of convincing evidence-based data available on incidence, demographics, natural history and managements of ITP. Retrospective case series, surveys, 49,50 guidelines, ${ }^{51,52}$ assessment and ${ }^{22}$ reports from expert meetings ${ }^{53,54}$ are the sources of information for patient management. As a result of the heterogeneity of ITP and various controversies, current practice does not always follow the recommendations. Prospective evidence-based studies are needed.

Since 1997, the ICIS group has established an international network of physicians and scientists collaborating in prospective databases and studies (see www.unibas.ch/itpbasel) that will define less heterogeneous patient subgroups for controlled treatment/management efficacy trials. The first results are promising. 2,3,25,55 The ongoing Paediatric and Adult Registry of Chronic (PARC) ITP database has the objective of defining subgroups within ITP on the basis of natural history, genetics, demographics, quality of life and other criteria.

One of the studies will focus on genetic differences. In these studies, polymorphisms and variations of genes ${ }^{12-14}$ in patients with ITP that may be involved in the loss of tolerance and unbalanced immune responses have shown variants in interleukin (IL)-1 haplotypes and an association with autoimmune disease.

The text represents the content of invited lectures at the 13th European Haematology Association, Copenhagen, at Europaediatrics 2008, Istanbul and at the XXXII World Congress of the International Society of Haematology 2008, Bangkok.
1. Zeller B, Rajantie J, Hedlund-Treutiger I, et al., NOPHO ITP. Childhood idiopathic thrombocytopenic purpura in the Nordic countries: epidemiology and predictors of chronic disease, Acta Paediatr, 2005;94(2):178-84.

2. Kühne $\mathrm{T}$, Imbach $\mathrm{P}$, Bolton-Maggs $\mathrm{PH}$, et al., Intercontinental Childhood ITP Study Group. Newly diagnosed idiopathic thrombocytopenic purpura in childhood: an observational study, Lancet, 2001;358(9299):2122-5.

3. Kühne T, Buchanan GR, Zimmerman $S$, et al., Intercontinental Childhood ITP Study Group; Intercontinental Childhood ITP Study Group. A prospective comparative study of 2540 infants and children with newly diagnosed idiopathic thrombocytopenic purpura (ITP) from the Intercontinental Childhood ITP Study Group, J Pediatr, 2003;143(5):605-8.

4. Kühne T, Berchtold W, Tran VB, et al., Ethnicity and environment may affect the phenotype of immune thrombocytopenic purpura in children, Pediatr Res, 2000;48(3): 374-9.

5. Cines $D B$, McMillan R, Pathogenesis of chronic immune thrombocytopenic purpura, Curr Opin Hematol, 2007;14(5): 511-14.

6. Negi VS, Elluru S, Sibéril S, et al., Intravenous immunoglobulin: an update on the clinical use and mechanisms of action, J Clin Immunol, 2007;27(3):233-45.

7. Lemieux R, Bazin R, Néron S, Therapeutic intravenous immunoglobulins, Mol Immunol, 2005:42(7):839-48.

8. Jin F, Balthasar JP, Mechanisms of intravenous immunoglobulin action in immune thrombocytopenic purpura, Hum Immunol, 2005;66(4):403-10.

9. Gold R, Stangel M, Dalakas MC, Drug Insight: the use of intravenous immunoglobulin in neurology —-therapeutic considerations and practical issues, Nat Clin Pract Neurol,
2007;3(1):36-44

10. Cines BD, ITP: "Time to bug off"?, Blood, 2007;110(12): 3818-19.

11. Emilia G, Luppi M, Zucchini P, et al., Helicobacter pylori infection and chronic immune thrombocytopenic purpura: long-term results of bacterium eradication and association with bacterium virulence profiles, Blood, 2007;110(12): 3833-41.

12. Foster CB, Zhu S, Erichsen HC, et al., Early Chronic ITP Study Group. Polymorphisms in inflammatory cytokines and Fcgamma receptors in childhood chronic immune thrombocytopenic purpura: a pilot study, Br I Haematol, 2001;113(3):596-9.

13. Satoh T, Pandey JP, Okazaki Y, et al., Single nucleotide polymorphisms of the inflammatory cytokine genes in adults with chronic immune thrombocytopenic purpura, $\mathrm{Br}$ J 
Haematol, 2004;124(6):796-801.

14. Sood R, Wong W, Jeng M, Zehnder JL, Gene expression profile of idiopathic thrombocytopenic purpura (ITP), Pediatr Blood Cancer, 2006;47(Suppl. 5):675-7.

15. Harrington WJ, Minnich V, Hollingsworth JW, Moore CV, Demonstration of a thrombocytopenic factor in the blood of patients with thrombocytopenic purpura, I Lab Clin Med, 1951;38(1):1-10.

16. Schwartz RS, Immune thrombocytopenic purpura—from agony to agonist, N Engl J Med, 2007;357(22):2299-2301.

17. Imbach P, Barandun S, d'Apuzzo V, et al., High-dose intravenous gammaglobulin for idiopathic thrombocytopenic purpura in childhood, Lancet, 1981;1(8232):1228-31.

18. Imbach P, Wagner HP, Berchtold W, et al., Intravenous immunoglobulin versus oral corticosteroids in acute immune thrombocytopenic purpura in childhood, Lancet, 1985;31; 2(8453):464-8.

19. Kuter DJ, New thrombopoietic growth factors, Blood, 20071;109(11):4607-16.

20. McMillan R, Wang L, Tomer A, et al., Suppression of in vitro megakaryocyte production by antiplatelet autoantibodies from adult patients with chronic ITP, Blood, 2004;103(4):1364-9.

21. Buchanan GR, Kühne T, Bolton-Maggs $P$, et al., Frequency, location and timing of severe hemorrhage in children with newly-diagnosed idiopathic thrombocytopenic purpura: study of the Intercontinental Childhood ITP Study Group, Blood, 2003;102:298a.

22. Bolton-Maggs PH, Moon I, Assessment of UK practice for management of acute childhood idiopathic thrombocytopenic purpura against published guidelines, Lancet, 1997;30; 350(9078):620-23.

23. Buchanan GR, Adix L, Grading of hemorrhage in children with idiopathic thrombocytopenic purpura, J Pediatr, 2002;141(5): $683-8$

24. Lilleyman JS, Intracranial haemorrhage in idiopathic thrombocytopenic purpura. Paediatric Haematology Forum of the British Society for Haematology, Arch Dis Child, 1994;71(3):251-3

25. Imbach $P$, Kühne T, Müller $D$, et al., Childhood ITP: 12 months follow-up data from the prospective registry I of the Intercontinental Childhood ITP Study Group (ICIS), Pediatr Blood Cancer, 2006:46(3):351-6.

26. Akatsuka J, Fujisawa K, Ishidoya N, et al., Long-term follow-up study of children with chronic ITP, Blut, 1989;59(1):105-8.

27. Tamary H, Kaplinsky C, Levy I, et al., Chronic childhood idiopathic thrombocytopenia purpura: long-term follow-up, Acta Paediatr, 1994;83(9):931-4.

28. Imbach P, Akatsuka J, Blanchette V, et al., Immunthrombocytopenic purpura as a model for pathogenesis and treatment of autoimmunity, Eur J Pediatr, 1995;154:60-64

29. Aronis S, Platokouki H, Mitsika A, et al., Seventeen years of experience with chronic idiopathic thrombocytopenic purpura in childhood. Is therapy always better?, Pediatr Hematol Oncol, 1994;11(5):487-98.

30. Klaassen RJ, Blancette VS, Barnard D, et al., Validity, relaibility, and responsiveness of a new measure of health-related quality of life in children with immune thrombocytopenic purpura: the Kids' ITP Tolls, J Pediatr, 2007;150:510-15.

31. Cines DB, Blanchette VS, Immune thrombocytopenic purpura, N Engl J Med, 2002;346(13):995-1008.

32. Blanchette $V$, Imbach $P$, Andrew $M$, et al., Randomised trial of intravenous immunoglobulin $G$, intravenous anti-D, and oral prednisone in childhood acute immune thrombocytopenic purpura, Lancet, 1994;344(8924):703-7.

33. Gaines $A R$, Disseminated intravascular coagulation associated with acute hemoglobinemia or hemoglobinuria following $\mathrm{Rh}(0)(\mathrm{D})$ immune globulin intravenous administration for immune thrombocytopenic purpura, Blood, 2005;106(5): $1532-7$

34. Tarantino MD, Young G, Bertolone SJ, et al., Acute ITP Study Group. Single dose of anti-D immune globulin at $75 \mu \mathrm{g} / \mathrm{kg}$ is as effective as intravenous immune globulin at rapidly raising the platelet count in newly diagnosed immune thrombocytopenic purpura in children, J Pediatr, 2006;148(4):489-94.

35. Newland A, Caulier MT, Kappers-Klunne M, et al., An open-label, unit dose-finding study of AMG 531, a novel thrombopoiesis-stimulating peptibody, in patients with immune thrombocytopenic purpura, Br J Haematol, 2006;135(4):547-53

36. Bussel JB, Kuter DJ, George JN, et al., AMG 531, a thrombopoiesis-stimulating protein, for chronic ITP, N Engl J
Med, 2006;355(16):1672-81.

37. Jenkins JM, Williams D, Deng Y, et al., Phase 1 clinical study of eltrombopag, an oral, nonpeptide thrombopoietin receptor agonist, Blood, 2007:109(11):4739-41.

38. Cines DB, Pumping out platelets, Blood, 2007;109(11):4591-92

39. Bussel JB, Cheng G, Saleh MN, Psaila B, Kovaleva L, Meddeb B, Kloczko J, Hassani H, Mayer B, et al., Eltrombopag for the treatment of chronic idiopathic thrombocytopenic purpura, N Engl J Med, 2007;357(22):2237-47.

40. Panzer $S$, New therapeutic options for adult chronic immune thrombocytopenic purpura: a brief review, Vox Sang, 2008;94(1):1-5.

41. Beck CE, Nathan PC, Parkin PC, et al., Corticosteroids versus intravenous immune globulin for the treatment of acute immune thrombocytopenic purpura in children: a systematic review and meta-analysis of randomized controlled trials, J Pediatr, 2005;147(4):521-7.

42. Wang J, Wiley JM, Luddy R, et al., Chronic immune thrombocytopenic purpura in children: assessment of rituximab treatment, J Pediatr, 2005;146(2):217-21.

43. Bennett CM, Rogers ZR, Kinnamon DD, et al., Prospective phase $1 / 2$ study of rituximab in childhood and adolescent chronic immune thrombocytopenic purpura, Blood, 2006;1; 107(7):2639-42.

44. Parodi E, Nobili B, Perrotta S, et al., Rituximab (anti-CD20 monoclonal antibody) in children with chronic refractory symptomatic immune thrombocytopenic purpura: efficacy and safety of treatment, Int J Hematol, 2006l;84(1):48-53.

45. Willis F, Marsh JC, Bevan DH, et al., The effect of treatment with Campath-1H in patients with autoimmune cytopenias, $\mathrm{Br}$. Haematol, 2001;114(4):891-8.

46. Kotb R, Pinganaud C, Trichet C, et al., Efficacy of mycophenolate mofetil in adult refractory auto-immune cytopenias: a single center preliminary study, Eur I Haematol, 2005;75(1):60-64

47. Andersen JC, Response of resistant idiopathic thrombocytopenic purpura to pulsed high-dose dexamethasone therapy, N Engl J Med, 1994;330(22):1560-64

48. Kühne T, Blanchette V, Buchanan GR, et al., Intercontinental Childhood ITP Study Group. Splenectomy in children with idiopathic thrombocytopenic purpura: A prospective study of 134 children from the Intercontinental Childhood ITP Study Group, Pediatr Blood Cancer, 2007;49(6):829-34.

49. Vesely S, Buchanan GR, Cohen A, et al., Self-reported diagnostic and management strategies in childhood idiopathic thrombocytopenic purpura: results of a survey of practicing pediatric hematology/oncology specialists, J Pediatr Hematol Oncol, 2000;22(1):55-61.

50. Vesely SK, Buchanan GR, Adix L, et al., American Society of Pediatric Hematology/Oncology, 2001. Self-reported initial management of childhood idiopathic thrombocytopenic purpura: results of a survey of members of the American Society of Pediatric Hematology/Oncology, 2001, J Pediatr Hematol Oncol, 2003:25(2):130-33.

51. George JN, Woolf SH, Raskob GE, et al., Idiopathic thrombocytopenic purpura: a practice guideline developed by explicit methods for the American Society of Hematology, Blood, 1996;88(1):3-40.

52. British Committee for Standards in Haematology General Haematology Task Force. Guidelines for the investigation and management of idiopathic thrombocytopenic purpura in adults, children and in pregnancy, Br J Haematol, 2003;120(4):574-96.

53. Imbach $P$, Kühne T, Blanchette $V$, Intercontinental Childhood ITP Study Group (ICIS). The State of the Art Expert Meeting of the Intercontinental Childhood ITP Study Group (ICIS), I Pediat Hematol Oncol, 2003;25(Suppl. 1):S1-84.

54. Kühne T, Imbach P, Critical Issues and Future Research of ITP, Pediatr Blood Cancer, 2006;47(Suppl. 5):649-745.

55. Kühne T, Blanchette V, Buchanan GR, et al., Intercontinental Childhood ITP Study Group. Splenectomy in children with idiopathic thrombocytopenic purpura: A prospective study of 134 children from the Intercontinental Childhood ITP Study Group, Pediatr Blood Cancer, 2007:49(6):829-34.

56. Chia WK, Blanchette V, Mody M, et al., Characterization of HIV-1-specific antibodies and HIV-1-crossreactive antibodies to platelets in HIV-1-infected haemophiliac patients, Br J Haematol, 1998;103(4):1014-22.

57. Blanchette V, Childhood chronic immune thrombocytopenic purpura (ITP), Blood Rev, 2002;16(1):23-6.
58. Li Z, Nardi MA, Karpatkin S, Role of molecular mimicry to HIV-1 peptides in HIV-1-related immunologic thrombocytopenia, Blood, 2005;106(2):572-6.

59. Siragam V, Crow AR, Brinc D, et al., Intravenous immunoglobulin ameliorates ITP via activating Fc gamma receptors on dendritic cells, Nat Med, 2006:12(6):688-92.

60. Siragam V, Brinc D, Crow AR, et al., Can antibodies with specificity for soluble antigens mimic the therapeutic effects of intravenous $\lg G$ in the treatment of autoimmune disease?, J Clin Invest, 2005;115(1):155-60.

61. Crow AR, Song S, Siragam V, Lazarus AH, Mechanisms of action of intravenous immunoglobulin in the treatment of immune thrombocytopenia, Pediatr Blood Cancer, 2006;47 (Suppl. 5):710-13.

62. Semple JW, Aslam R, Kim M, et al., Platelet-bound lipopolysaccharide enhances $\mathrm{Fc}$ receptor-mediated phagocytosis of IgG-opsonized platelets, Blood, 2007;109(11):4803-5.

63. Semple JW, Bruce S, Freedman J, Suppressed natural killer cell activity in patients with chronic autoimmune thrombocytopenic purpura, Am J Hematol, 1991;37(4):258-62.

64. Semple JW, Milev Y, Cosgrave D, et al., Differences in serum cytokine levels in acute and chronic autoimmune thrombocytopenic purpura: relationship to platelet phenotype and antiplatelet T-cell reactivity, Blood, 1996;87(10):4245-54

65. Tha-In T, Metselaar HJ, Tilanus HW, et al., Intravenous immunoglobulins suppress T-cell priming by modulating the bidirectional interaction between dendritic cells and natural killer cells, Blood, 2007:110(9):3253-62.

66. Kappers-Klunne MC, van't Veer MB, Cyclosporin A for the treatment of patients with chronic idiopathic thrombocytopenic purpura refractory to corticosteroids or splenectomy, $\mathrm{Br}$ 」 Haematol, 2001;114(1):121-5.

67. Emilia G, Morselli M, Luppi M, et al., Long-term salvage therapy with cyclosporin $\mathrm{A}$ in refractory idiopathic thrombocytopenic purpura, Blood, 2002;99(4):1482-5.

68. Hrstková H, Bajer M, Michálek J, Recombinant human interferon alpha-2a therapy in children with chronic immune thrombocytopenic purpura, I Pediatr Hematol Oncol, 2002;24(4):299-303.

69. Teeling JL, Jansen-Hendriks T, Kuijpers TW, et al., Therapeutic efficacy of intravenous immunoglobulin preparations depends on the immunoglobulin $\mathrm{G}$ dimers: studies in experimental immune thrombocytopenia, Blood, 2001;98(4):1095-9.

70. Bennett $C M$, Rogers $Z R$, Kinnamon $D D$, et al., Prospective phase $1 / 2$ study of rituximab in childhood and adolescent chronic immune thrombocytopenic purpura, Blood, 2006; 107(7):2639-42.

71. Stasi R, Del Poeta G, Stipa E, et al., Response to B-cell depleting therapy with rituximab reverts the abnormalities of T-cell subsets in patients with idiopathic thrombocytopenic purpura, Blood, 2007;110(8):2924-30.

72. Kjaersgaard $M$, Aslam R, Kim M, et al., Epitope specificity and isotype of monoclonal anti-D antibodies dictate their ability to inhibit phagocytosis of opsonized platelets, Blood, 2007;110(4): 1359-61.

73. Arnold DM, Dentali F, Crowther MA, et al., Systematic review: efficacy and safety of rituximab for adults with idiopathic thrombocytopenic purpura, Ann Intern Med, 2007:146(1): 25-33.

74. Samuelsson A, Towers TL, Ravetch JV, Anti-inflammatory activity of IVIG mediated through the inhibitory Fc receptor Science, 2001;291(5503):484-6.

75. Ravetch JV, Bolland S, IgG Fc receptors, Annu Rev Immunol, 2001:19:275-90

76. Viard I, Wehrli P, Bullani R, et al., Inhibition of toxic epidermal necrolysis by blockade of CD95 with human intravenous immunoglobulin, Science, 1998;282(5388):490-93.

77. Salama A, Kiefel V, Mueller-Eckhardt C, Effect of lgG anti-Rho(D) in adult patients with chronic autoimmune thrombocytopenia, Am J Hematol, 1986;22(3):241-50.

78. Andrew M, Blanchette VS, Adams $\mathrm{M}$, et al., A multicenter study of the treatment of childhood chronic idiopathic thrombocytopenic purpura with anti-D, J Pediatr, 1992;120 $522-7$

79. Borgna-Pignatti C, Battisti L, Zecca M, Locatelli F, Treatment of chronic childhood immune thrombocytopenic purpura with intramuscular anti-D immunoglobulins, Br I Haematol, 1994;88(3):618-20. 